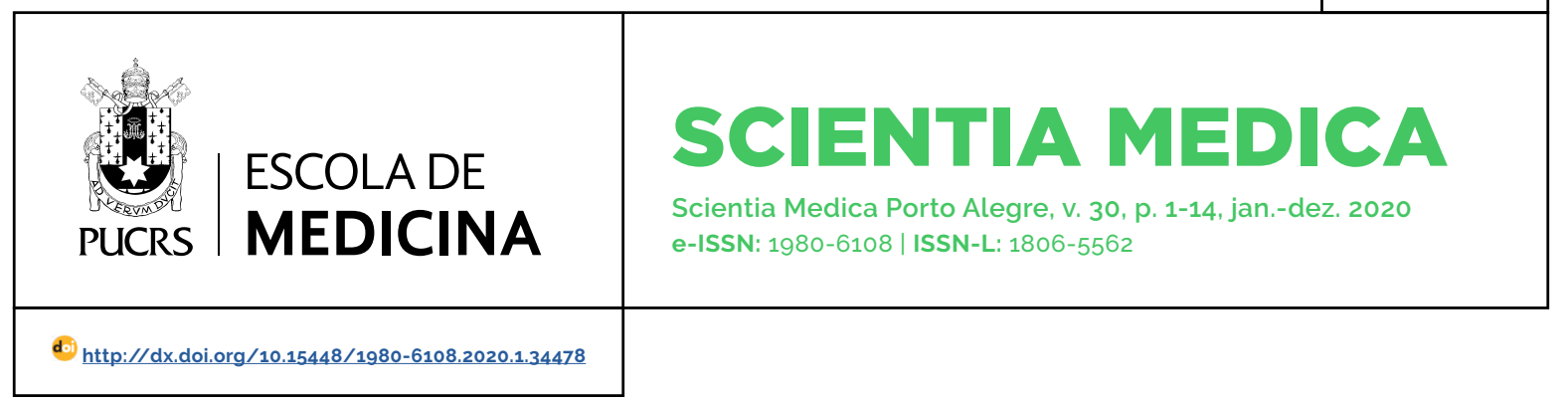

ORIGINAL ARTICLE

\title{
Potentially inappropriate medication and associated factors such as depression and dementia: An analysis of middle-aged and elderly people
}

\author{
Prevalência de medicamentos potencialmente inapropriados e fatores associados, \\ como depressão e demência: uma análise de pessoas de meia-idade e idosos
}

\author{
Vanessa Sgnaolin ${ }^{1}$ \\ orcid.org/0000-0002-9914-7146 \\ vanessasgnaolin@yahoo.com.br
}

\section{Paula Engroff ${ }^{2}$ \\ orcid.org/0000-0002-3639-545X \\ paula_puc@yahoo.com.br}

\section{Natascha Melo}

Linkievicz ${ }^{3}$

orcid.org/0000-0002-0859-0717

nataschamel@gmail.com

\section{Irenio Gomes ${ }^{1}$}

orcid.org/0000-0003-2083-5059

irenio@nienpe.org

\section{Alfredo Cataldo Neto 4 orcid.org/0000-0002-8082-1866 cataldo@pucrs.br}

Recebido em: 13 jun.2019. Aprovado em: 26 mar. 2020 Publicado em: 15 jul. 2020

\section{(c) (1)}

Artigo está licenciado sob forma de uma licença Creative Commons Atribuição 4.0 Internacional.

\section{ABSTRACT}

AIMS: To establish the frequency potentially inappropriate medications use and the associated factors, such as signs and symptoms of depression and cognitive deficit among middle-aged and elderly people.

METHODS: A cross-sectional population study was performed with 2,350 people, aged between 55-103 years, registered in the primary health care. Potentially inappropriate medications were defined by updated 2019 Beers criteria. Studied variables were sociodemographic, lifestyle and health, and signs and symptoms of depression and cognitive deficit. Multinomial regression analysis was executed. RESULTS: The frequency of potentially inappropriate medications use was $65.4 \%$. Former and current smokers, regular self-perception of health, polypharmacy, and individuals with signs and symptoms of depression and cognitive deficit were significantly associated with potentially inappropriate medications use. Antiarrhythmics, antihistamines and antiadrenergic agents were the highest potentially inappropriate medications classes used for individuals with signs and symptoms of depression and cognitive deficit.

CONCLUSIONS: The frequency of use of potentially inappropriate medications is high among middle-aged people, a population that was previously under-researched, as well as among elderly people. Cognitive impairment alone or together with depression symptoms were associated factor for a potentially inappropriate medications use. Knowledge of the pharmacoepidemiology of potentially inappropriate medications is an important for the promotion of the rational use of drugs in public health.

KEYWORDS: potentially inappropriate medication list; middle aged; aged depression; dementia; public health

\section{RESUMO}

OBJETIVOS: Estabelecer a frequência de uso de medicamentos potencialmente inapropriados e fatores associados, tais como sinais e sintomas de depressão e déficit cognitivo, em individuos de meia-idade e idosos.

MÉTODOS: Estudo transversal de base populacional com 2.350 individuos, de idade entre 55 e 103 anos, cadastrados na atenção primária à saúde. Medicamentos potencialmente inapropriados foram definidos pelos Critérios Beers atualizados em 2019. As variáveis estudadas foram sociodemográficas, estilo de vida, clínicas, bem como sinais e sintomas de depressão e déficit cognitivo. Foi realizada análise de regressão multinomial.

\footnotetext{
Pontifícia Universidade Católica do Rio Grande do Sul (PUCRS), Graduate Program in Biomedical Gerontology. Porto Alegre, RS, Brasil Pontificia Universidade Católica do Rio Grande do Sul (PUCRS), Institute of Geriatrics and Gerontology. Porto Alegre, RS, Brasil Pontificia Universidade Católica do Rio Grande do Sul (PUCRS), School of Health and Life Sciences. Porto Alegre, RS, Brasil Pontifícia Universidade Católica do Rio Grande do Sul (PUCRS), School of Medicine and Graduate Program in Biomedical Gerontology. Porto Alegre, RS, Brasil
} 
RESULTADOS: A frequência de uso de medicamentos potencialmente inapropriados foi de $65,4 \%$. O uso de medicações potencialmente inapropriadas foi significativamente associado a individuos ex-fumantes e fumantes atuais, com autopercepção de saúde regular, usuários de polifarmácia e com sinais e sintomas de depressão e déficit cognitivo. Antiarritmicos, anti-histamínicos e antiadrenérgicos foram as classes de medicamentos potencialmente inapropriados mais utilizada pelos individuos com sinais e sintomas de depressão e déficit cognitivo.

CONCLUSÕES: A frequência de utilização de medicamentos potencialmente inapropriados é alta em pessoas de meia-idade, faixa etária pouco pesquisada, bem como em idosos. O comprometimento cognitivo, isoladamente ou em conjunto com sintomas de depressão, foi um fator associado ao uso de medicações potencialmente inapropriadas. O conhecimento da farmacoepidemiologia de utilização de medicamentos potencialmente inapropriados é importante para a promoção do uso racional de medicamentos na saúde pública.

DESCRITORES: lista de medicamentos potencialmente inapropriados; meia-idade; idoso; depressão; demência; saúde pública.

ABBREVIATIONS: FHS, Family Health Strategy; GDS-15, Geriatric Depression Scale abbreviate; PENCE, Programa de Envelhecimento Cerebral; PIM, Potentially Inappropriate Medication; SED, socioeconomic disadvantage.

\section{INTRODUCTION}

People worldwide are living longer. Between 2015 and 2050, the proportion of the world's population over 60 years will nearly double from $12 \%$ to $22 \%$ [1]. The elderly population is one of the most vulnerable in terms of health. One related factor to poor health in the elderly is socioeconomic disadvantage (SED) status. Education, place of residence, health beliefs and behavior, occupation, income, access to health services and the environment in which people live contribute to low health status in the middleaged and elderly [2].

Aging has a great impact on social and health care policy planning, because there is a growing burden of underlying diseases. One difficulty in prescribing for multimorbid patients is the risk of Potentially Inappropriate Medication (PIM). PIM use may occur whenever the benefits of using some medications are outweighed by the risks and/or whenever avoidance of drug use in specific settings is suggested by scientific evidence [3]. It is a common problem in older persons, ranging from a prevalence of $11.5 \%$ to $62.5 \%$ of the elderly population. It is associated with adverse effects, hospitalization, morbidity, mortality and high health services cost [4].

One way to identify PIM prescribing is to use validated screening tools that incorporate explicit prescribing indicators, such as the Beers criteria that is the most widely used approach to assess the quality of drug prescribing among the elderly [5]. This tool provides a list of PIM or drug classes that should generally be avoided in the treatment of elderly [6]. There are other international criteria have been defined with the intent of preventing PIM for elderly [7-10].

Traditionally, the focus of PIM has been on older people (especially those $\geq 65$ years) due to the high frequency of medication use in this age group and the organic aging process. However, there is evidence that multimorbidity is also prevalent in middle-aged people [11]. As yet, there has been little consideration of PIM in this age group [2].

Depression and cognitive disorders, including dementia, are common in aging [12, 13]. Most research on PIM has focused on the elderly rather than depression and dementia specifically [14. 15]. Barbiturates, phenytoin, and benzodiazepines are some examples of drug classes that cause deterioration of several basic human abilities: concentration, mental energy, mood and memory [13].

The objectives were to determine the frequency of PIM use and associated factors, among them signs and symptoms of depression and cognitive deficit in middle-aged and elderly people.

\section{METHODS}

\section{Setting}

This study involved a subset of patients of the Brain Aging Program (PENCE, Programa de Envelhecimento Cerebral) in Porto Alegre City, Brazil. The collection of data related to this study took place from January 2013 to December 2015 and enrolled individuals registered on the Family Health Strategy (FHS) of the Hospital São Lucas catchment area of Porto Alegre City. 
The FHS is a proactive community public health care approach implemented by the Brazilian Ministry of Health. It is characterized by active and continued health promotion and monitoring at the community level. The FHS prioritizes locations with people living in SED and identifies and enrolls all local inhabitants based on their dwelling place (geographic-based registration) covered by each FHS team. For the constitution of PENCE, initially and continuously, the community health agents of the FHS teams were trained to use the research tools.

\section{Study Design and Population}

A cross-sectional population-based survey study design was developed to evaluate the association between the presence of PIM and sociodemographic, lifestyle and health predictors, with a focus on the signs and symptoms of depression and cognitive deficit. The target population of the study was individuals of both sexes that were 55 years of age or older. Adults aged 55 to 59 years were classified as middleaged, and those aged 60 years or more were called the elderly. For inclusion in the study, it was necessary that the patients used at least one medication continuously.

\section{Outcome and variables studied}

The primary determinant was the presence of PIM, which was initially identified using the 2015 Beers criteria [16]. In 2019 Beers criteria went through an update which implied an adjustment of the data presented for this new version [6]. To assess a complete pharmacological evaluation, community health workers revised all drugs regularly used together with participants (and with their representatives if necessary) as part of a wide multidimensional evaluation designed for the PENCE to optimize information since the first homevisit approach in the registration. If the individual were previously enrolled, a complementary home visit included data to improve or complement information of the medical records at the FHS. Subsequently, drugs were coded according to the
Anatomical Therapeutic Chemical Classification system recommended by the World Health Organization [17]. The community health workers have previously received training in order to qualify and standardize the data collection.

In this study, 48 PIM items were identified irrespective of disease diagnoses or conditions. Dimenhydrinate, meclizine, meperidine and mineral oil were not used by any patient. Acetylsalicylic acid and insulin, which are inappropriate only for certain conditions, were not included in this study, because we did not have the information on the dosages and the form of release of these drugs. Drugs that are not available in the Brazil were not considered.

The following covariates from the PENCE study were examined as potential associated factors:

- Socioeconomic status (sex, age, education level, marital status/living with a partner, individual and family income: the last measured in relation to the minimum Brazilian wage of USD 280);

- Lifestyle information, including smoking habits (current, ex, or never) and alcohol use (dichotomous)

- Self-perceived health (examined as very good/good vs. regular vs. bad/very bad), number of comorbidities (according to number of chronic diseases by self-report of the patient);

- Number of drugs prescribed. As polypharmacy users were classified individuals who used five or more medications.

The presence of depressive symptoms was ascertained using the Geriatric Depression Scale abbreviate (GDS-15). Patients with a GDS-15 score equal to or greater than six were considered depressed [18]. Cognitive function was obtained using the Vellore Screening Instrument for Dementia [19], which is composed of 10 cognitive patient test items and 10 informant items. To consider presence of signs or symptoms of cognitive deficit, the questionnaire score for the patient needed to be $\leq 11$ points or the 
questionnaire score for the informant needed to be equal to or greater than five points. Was used the classification "normal" or "impaired".

\section{Statistical analysis}

Data were analyzed using the software IBM SPSS Statistics 20.0. The variables were described in terms of frequency, mean and standard deviation. Associations between categorical variables were tested using Pearson's chisquare test. In specific cases, the chi-square test for linear tendency (ordinal variables with few categories) was used. To compare the means between the groups was used analysis of variance (one-way ANOVA). In the comparison of dichotomous variables with a quantitative variable large sample size or normal distribution, we used the Student's $t$-test (taking into account the equality of variance tested by Levene test). To examine independent factors related to PIM and to improve control for confounding variables a multivariate analysis through multinomial logistic regression was performed. The model entry criterion for independent variables was $P<0.20$ in the univariate analyses. All variables with $P<0.05$ remained in the final model. The predetermined level of significance used was $P<0.05$. Confidence intervals of $95 \%$ were used for all calculations.

\section{Ethical considerations}

This study was approved by the Ethical Research Committee of the Pontifical Catholic University of Rio Grande do Sul (number 826.858) and Porto Alegre Municipal Secretariat of Health (number 1.003.962), according to the Guidelines and Norms Regulating Research of Resolution $466 / 12$ of the National Health Council of the Ministry of Health.

\section{RESULTS}

The 2,350 individuals included in the study were aged between 55 and 103 years (mean age, $67.3 \pm 8.6$ years), and comprised mostly females (70.5\%). Many of these people had four to seven years of education (36.7\%), were married or in a stable union (43.5\%) and lived with a partner (49.9\%). More than half received less than the minimum monthly wage (59.1\%) and a little more than half of the households (57.2\%) received one to three minimum wages.

The frequency of PIM was $65.4 \%$. Table 1 shows the association between PIM with sociodemographic variables. The presence of PIM was associated with increasing age ( 70 years or older) and more years of study (8 years or more). It is important to note that at all levels, PIM frequency was high, even among middleaged (63.0\%) and illiterate (59.6\%) individuals. We found an association between lifestyle and health data, and PIM (Table 2). Individuals who did not consume alcohol, who presented a poorer selfperception of health, who had a greater number of chronic diseases (especially two or more), and who used polypharmacy, and those with changes in instruments GDS-15, Vellore or both had a higher frequency of PIM use. 
TABLE 1 - Potentially Inappropriate Medication (PIM) according to the sociodemographic variables in the PENCE study $(\mathrm{n}=2,350)$.

\begin{tabular}{|c|c|c|c|c|c|}
\hline \multirow{2}{*}{ Variables } & \multirow{2}{*}{$\begin{array}{c}\text { Population } \\
\mathrm{n}(\%)\end{array}$} & \multicolumn{2}{|c|}{ PIM-Users } & \multicolumn{2}{|c|}{ PIM Number } \\
\hline & & $\%$ & $P$ & $M \pm S D$ & $P$ \\
\hline \multicolumn{6}{|l|}{ Gender } \\
\hline $\begin{array}{l}\text { Male } \\
\text { Female }\end{array}$ & $\begin{array}{l}693(29.5) \\
1657(70.5)\end{array}$ & $\begin{array}{l}66.1 \\
65.2\end{array}$ & $0.672^{*}$ & $\begin{array}{l}2.01 \pm 0.95 \\
1.98 \pm 1.06\end{array}$ & $0.656^{+}$ \\
\hline \multicolumn{6}{|l|}{ Age (years) } \\
\hline $55-59$ & $494(21.3)$ & 63.0 & \multirow{4}{*}{$0.001^{\ddagger}$} & $1.94 \pm 1.02$ & \multirow{4}{*}{$0.663^{5}$} \\
\hline $60-69$ & $986(42.6)$ & 62.5 & & $2.00 \pm 1.08$ & \\
\hline $70-79$ & $600(25.9)$ & 69.5 & & $2.03 \pm 1.02$ & \\
\hline$\geq 80$ & $235(10.2)$ & 72.3 & & $1.96 \pm 0.88$ & \\
\hline \multicolumn{6}{|l|}{ Education (years) } \\
\hline 0 & $257(11.2)$ & 59.6 & \multirow{4}{*}{$0.005^{\ddagger}$} & $2.00 \pm 1.08$ & \multirow{4}{*}{$0.500^{5}$} \\
\hline $1-3$ & $604(26.3)$ & 64.7 & & $2.05 \pm 1.04$ & \\
\hline $4-7$ & $842(36.7)$ & 66.4 & & $1.95 \pm 0.96$ & \\
\hline$\geq 8$ & $580(25.3)$ & 69.3 & & $2.01 \pm 1.10$ & \\
\hline \multicolumn{6}{|l|}{ Marital status } \\
\hline Single & $385(16.9)$ & 62.3 & \multirow{4}{*}{$0.411^{\star}$} & $1.91 \pm 1.00$ & \multirow{4}{*}{$0.551^{5}$} \\
\hline Married/stable union & $994(43.5)$ & 66.1 & & $1.99 \pm 1.01$ & \\
\hline Divorced & $251(11.0)$ & 68.5 & & $2.03 \pm 1.18$ & \\
\hline Widowed & $654(28.6)$ & 65.6 & & $2.03 \pm 1.01$ & \\
\hline \multicolumn{6}{|l|}{ Living with partner } \\
\hline No & $1073(50.1)$ & 65.5 & \multirow{2}{*}{$0.966^{*}$} & $2.00 \pm 1.04$ & \multirow{2}{*}{0.855} \\
\hline Yes & $1067(49.9)$ & 65.6 & & $1.99 \pm 1.01$ & \\
\hline \multicolumn{6}{|c|}{ Individual income (minimum wage) } \\
\hline 0 & $195(9.6)$ & 62.1 & \multirow{4}{*}{$0.477^{\ddagger}$} & $1.99 \pm 1.02$ & \multirow{4}{*}{$0.851^{5}$} \\
\hline$<1$ & $1002(49.5)$ & 67.8 & & $2.04 \pm 1.04$ & \\
\hline$\geq 1-2$ & $612(30.2)$ & 67.3 & & $1.99 \pm 1.01$ & \\
\hline$\geq 2$ & $215(10.6)$ & 60.0 & & $2.02 \pm 1.03$ & \\
\hline \multicolumn{6}{|c|}{ Family income (minimum wage) } \\
\hline$<1$ & $554(29.4)$ & 67.0 & & $1.99 \pm 1.04$ & \\
\hline$\geq 1-3$ & $1078(57.2)$ & 65.8 & $0.821^{\ddagger}$ & $2.02 \pm 1.03$ & $0.560^{5}$ \\
\hline$\geq 3$ & $252(13.4)$ & 66.7 & & $2.10 \pm 1.06$ & \\
\hline TOTAL POPULATION & $2350(100)$ & 65.4 & & $1.99 \pm 1.03$ & \\
\hline
\end{tabular}

M, mean; SD, standard deviation; PENCE, Brain Aging Program; PIM, Potentially Inappropriate Medication. *Pearson's chi-square test; ‘Student $t$ test; ${ }^{\ddagger}$ Chi-square test for linear tendency; ${ }^{5}$ One-way ANOVA. Minimum wage USD $280,00$. 
TABLE 2 - Potentially Inappropriate Medication (PIM) according to the lifestyle and health variables in the PENCE study $(\mathrm{n}=2,350)$.

\begin{tabular}{|c|c|c|c|c|c|}
\hline \multirow{2}{*}{ Variables } & \multirow{2}{*}{$\begin{array}{c}\text { Population } \\
n(\%)\end{array}$} & \multicolumn{2}{|c|}{ PIM-Users } & \multicolumn{2}{|c|}{ PIM Number } \\
\hline & & $\%$ & $P$ & $M \pm S D$ & $P$ \\
\hline \multicolumn{6}{|l|}{ Smoker } \\
\hline No (never) & $976(43.2)$ & 63.8 & & $1.98 \pm 1.02$ & \\
\hline Ex-smoker & $852(37.7)$ & 68.7 & $0.072^{*}$ & $2.03 \pm 1.03$ & $0.402^{5}$ \\
\hline Yes & $430(19.0)$ & 64.2 & & $1.94 \pm 1.04$ & \\
\hline \multicolumn{6}{|l|}{ Alcohol use } \\
\hline No & $1716(78.1)$ & 67.8 & & $1.99 \pm 1.03$ & \\
\hline Yes & $482(21.9)$ & 59.8 & $0.001^{*}$ & $1.97 \pm 1.00$ & $0.699^{\ddagger}$ \\
\hline \multicolumn{6}{|l|}{ Self-perceived health } \\
\hline Great/Good & $913(39.3)$ & 55.0 & & $1.80 \pm 0.93$ & \\
\hline Regular & $1179(50.7)$ & 70.9 & $<0.001^{+}$ & $2.04 \pm 1.01$ & $<0.001^{5}$ \\
\hline Poor/Very poor & $234(10.1)$ & 78.6 & & $2.29 \pm 1.25$ & \\
\hline \multicolumn{6}{|c|}{ Number of chronic diseases } \\
\hline 0 & $257(11.3)$ & 53.7 & & $1.57 \pm 0.86$ & \\
\hline 1 & $877(38.4)$ & 53.7 & $<0.001^{+}$ & $1.72 \pm 0.93$ & $<0.001^{\mathrm{S}}$ \\
\hline 2 & $623(27.3)$ & 71.4 & & $2.07 \pm 1.00$ & \\
\hline$\geq 3$ & $524(23.0)$ & 84.5 & & $2.37 \pm 1.08$ & \\
\hline \multicolumn{6}{|l|}{ Number of drugs } \\
\hline $1-2$ & $623(26.5)$ & 31.3 & & $1.22 \pm 0.45$ & \\
\hline $3-4$ & $721(30.7)$ & 59.9 & $<0.001^{+}$ & $1.60 \pm 0.70$ & $<0.001^{\mathrm{s}}$ \\
\hline$\geq 5$ (Polypharmacy) & $1006(42.8)$ & 90.6 & & $2.34 \pm 1.09$ & \\
\hline \multicolumn{6}{|c|}{ Depression and/or cognitive deficit } \\
\hline Normal & $1305(56.0)$ & 60.1 & & $1.91 \pm 0.95$ & \\
\hline Depression & $548(23.5)$ & 70.4 & & $2.13 \pm 1.15$ & \\
\hline Cognitive déficit & $180(7.7)$ & 72.2 & $<0.001^{*}$ & $1.86 \pm 0.85$ & $0.001^{\S}$ \\
\hline $\begin{array}{l}\text { Depression and } \\
\text { cognitive deficit }\end{array}$ & $296(12.7)$ & 77.7 & & $2.09 \pm 1.12$ & \\
\hline Total Population & $2350(100)$ & 65.4 & & $1.99 \pm 1.03$ & \\
\hline
\end{tabular}

M, mean; SD, standard deviation; PENCE, Brain Aging Program. *Pearson's chi-square test; ${ }^{+}$Chi-square test for linear tendency; łStudent $t$ test; ${ }^{\circledR}$ One way ANOVA.

To identify associated factors with PIM prescription in users, multinomial logistic regression analysis was conducted (Table 3 ). When mutually adjusting for all variables presented in the table 3, associated factors with PIM prescribing were: being an ex-smoker (OR $=1.06 ; 95 \% \mathrm{Cl}=1.00$ - 1.12) or current smoker (OR = 1.10; $95 \% \mathrm{Cl}=1.02$ 1.18), regular self-perception of health $(O R=1.09$; 
$95 \% \mathrm{Cl}=1.02-1.16)$, taking three or four drugs (OR = 1.88; $95 \% \mathrm{Cl}=1.65-2.15)$, especially those exposed to polypharmacy $(\mathrm{OR}=2.80 ; 95 \% \mathrm{Cl}=2.48-3.16)$, and individuals with instruments Vellore-classified as impaired $(\mathrm{OR}=1.14 ; 95 \% \mathrm{Cl}=1.03-1.26)$ and both GDS-15 and Vellore-presented altered results (OR $=1.12 ; 95 \% \mathrm{Cl}=1.04-1.21$.

TABLE 3 - Multivariate analysis of the associated factors with Potentially Inappropriate Medication (PIM) in the PENCE study $(\mathrm{n}=2,350)$.

\begin{tabular}{|c|c|c|c|}
\hline \multirow{2}{*}{ Variables } & \multicolumn{3}{|c|}{ PIM-Users } \\
\hline & OR & $\mathrm{Cl} 95 \%$ & $P$ \\
\hline \multicolumn{4}{|l|}{ Smoker } \\
\hline No (never) & 1 & & \\
\hline Ex-smoker & 1.06 & $(1.00-1.12)$ & 0.044 \\
\hline Yes & 1.10 & $(1.02-1.18)$ & 0.018 \\
\hline \multicolumn{4}{|l|}{ Self-perceived health } \\
\hline Great/Good & 1 & & \\
\hline Regular & 1.09 & $(1.02-1.16)$ & 0.011 \\
\hline Poor/Very poor & 1.07 & $(0.98-1.17)$ & 0.130 \\
\hline \multicolumn{4}{|l|}{ Number of drugs } \\
\hline $1-2$ & 1 & & \\
\hline $3-4$ & 1.88 & $(1.65-2.15)$ & $<0.001$ \\
\hline$\geq 5$ (Polypharmacy) & 2.80 & $(2.48-3.16)$ & $<0.001$ \\
\hline \multicolumn{4}{|l|}{ Depression and/or cognitive deficit } \\
\hline Normal & 1 & & \\
\hline Depression & 1.02 & $(0.96-1.09)$ & 0.473 \\
\hline Cognitive deficit & 1.14 & $(1.03-1.26)$ & 0.009 \\
\hline Depression and cognitive deficit & 1.12 & $(1.04-1.21)$ & 0.002 \\
\hline
\end{tabular}

$\mathrm{Cl}$, confidence interval; OR, odds ratio; PENCE, Brain Aging Program. PIM, Potentially Inappropriate Medication. Regression logistic multinomial.

Among the drugs which were most frequently prescribed, the study found that the most common was omeprazole (25.5\% total population; 39.2\% PIM-users) followed by glibenclamide (8.9\% total population; 13.6\% PIM-users), amitriptyline (6.1\% total population; 9.3\% PIM-users), ibuprofen (5.5\% total population; 8.5\% PIM-users) and diazepam (4.3\% total population; 6.7\% PIM-users).

Table 4 presents the results of the multivariate analysis for the PIM use. The results were classified according to their pharmacology class of individuals who exhibit signs and symptoms of depression (GDS-15) and/or cognitive deficit (Vellore). Individuals with symptoms of depression make more use of antiadrenergic agents, centrally acting $(\mathrm{OR}=3.63 ; 95 \% \mathrm{Cl}=1.35-9.78)$ and antihistamines for systemic use (OR 5.33; 95\% Cl = $1.93-14.73$ ). Antiarrhythmics (class I and III) $(O R=11.14 ; 95 \% \mathrm{Cl}$ $=2.58$ - 48.09), anxiolytics (OR = 2.83; $95 \% \mathrm{Cl}=1.65$ - 4.86), antidepressants (OR $=2.28 ; 95 \% \mathrm{Cl}=1.46$ 3.55) and antihistamines for systemic use $(\mathrm{OR}=3.56$; $95 \% \mathrm{Cl}=1.04-12.21$ ) were more prescribed for those with signs and symptoms of both depression and cognitive impairment. The blood glucose lowering drugs (excluded insulin) $(O R=0.53 ; 95 \% \mathrm{Cl}=0.31$ 0.91 were prescribed less for this latter group. This analysis was adjusted by smoker, self-perception health and number of drugs variables. 
TABLE 4 - Potentially Inappropriate Medication (PIM) according to their pharmacology class, among individuals who exhibit signs and symptoms of depression and/or cognitive deficit.

\begin{tabular}{|c|c|c|c|c|c|c|c|c|}
\hline \multirow{2}{*}{ ATCC } & \multirow{2}{*}{ Variable } & \multirow[t]{2}{*}{ Normal } & \multicolumn{2}{|c|}{ Depression } & \multicolumn{2}{|c|}{ Cognitive Deficit } & \multicolumn{2}{|c|}{$\begin{array}{l}\text { Depression and } \\
\text { Cognitive Deficit }\end{array}$} \\
\hline & & & n (\%) & OR (Cl 95\%) & n (\%) & OR (Cl 95\%) & n (\%) & OR (CI 95\%) \\
\hline $\mathrm{Ao} 2 \mathrm{~B}$ & $\begin{array}{l}\text { Drugs for peptic } \\
\text { ulcer and gastro-oe- } \\
\text { sophageal reflux }\end{array}$ & 305 (38.9) & $168(43.5)$ & $1.09(0.83-1.43)$ & $44(33.8)$ & $0.75(0.49-1.13)$ & $87(37.8)$ & $0.92(0.65-1.28)$ \\
\hline $\mathrm{A} 10 \mathrm{~B}$ & $\begin{array}{l}\text { Blood glucose } \\
\text { lowering drugs, excl. } \\
\text { Insulins }\end{array}$ & $120(15.3)$ & $52(25.0)$ & $0.86(0.59-1.26)$ & $15(11.5)$ & $0.71(0.39-1.30)$ & $21(9.1)$ & $0.53(0.31-0.91)^{\ddagger}$ \\
\hline $\mathrm{CO1A}$ & Cardiac glycosides & $19(2.4)$ & $18(4.7)$ & $1.74(0.86-3.52)$ & $5(3.8)$ & $1.87(0.67-5.18)$ & $7(3.0)$ & $1.29(0.49-3.38)$ \\
\hline Co1B & $\begin{array}{l}\text { Antiarrhythmics, } \\
\text { class i and iii }\end{array}$ & $3(0.4)$ & $4(1.0)$ & $3.59(0.78-16.61)$ & $1(0.8)$ & $2.10(0.21-20.49)$ & $6(2.6)$ & $\begin{array}{c}11.14(2.58- \\
48.09)^{+}\end{array}$ \\
\hline $\mathrm{Co} 2 \mathrm{~A}$ & $\begin{array}{l}\text { Antiadrenergic } \\
\text { agents, centrally } \\
\text { acting }\end{array}$ & $7(0.9)$ & $11(2.8)$ & $3.63(1.35-9.78)^{\ddagger}$ & $1(0.8)$ & $0.88(0.11-7.27)$ & $3(1.3)$ & $1.71(0.42-7.01)$ \\
\hline $\mathrm{Co} 2 \mathrm{C}$ & $\begin{array}{l}\text { Antiadrenergic } \\
\text { agents, peripherally } \\
\text { acting }\end{array}$ & $17(2.2)$ & $4(1.0)$ & $0.50(0.15-1.62)$ & $4(3.1)$ & $1.49(0.49-4.56)$ & $3(1.3)$ & $0.59(0.15-2.31)$ \\
\hline Mo1A & $\begin{array}{l}\text { Antiinflammatory } \\
\text { and antirheumatic, } \\
\text { non-steroids }\end{array}$ & $86(11.0)$ & $41(10.6)$ & $0.89(0.58-1.37)$ & $14(10.8)$ & $0.99(0.54-1.82)$ & $28(12.2)$ & $1.06(0.64-1.75)$ \\
\hline Mo3B & $\begin{array}{l}\text { Muscle relaxants, } \\
\text { centrally acting } \\
\text { agents }\end{array}$ & $20(2.6)$ & $10(2.6)$ & $0.77(0.32-1.84)$ & $1(0.8)$ & $0.28(0.04-2.16)$ & $6(2.6)$ & $0.60(0.20-1.78)$ \\
\hline No3A & Antiepileptics & $32(4.1)$ & $28(7.3)$ & $1.62(0.93-2.83)$ & $6(4.6)$ & $1.10(0.45-2.70)$ & $19(8.3)$ & $1.74(0.91-3.33)$ \\
\hline No5B & Anxiolytics & $38(4.8)$ & $36(9.3)$ & $1.47(0.88-2.46)$ & 9 (6.9) & $1.32(0.60-2.92)$ & $34(14.8)$ & $2.83(1.65-4.86)^{\circ}$ \\
\hline No6A & Antidepressants & $78(9.9)$ & $50(13.0)$ & $1.38(0.92-2.06)$ & $13(10.0)$ & $0.99(0.53-1.85)$ & $47(20.4)$ & $2.28(1.46-3.55)^{\circ}$ \\
\hline Ro6A & $\begin{array}{l}\text { Antihistamines for } \\
\text { systemic use }\end{array}$ & $6(0.8)$ & $15(3.9)$ & $5.33(1.93-14.73)^{+}$ & $1(0.8)$ & $1.00(0.12-8.41)$ & $6(2.6)$ & $3.56(1.04-12.21)^{\ddagger}$ \\
\hline
\end{tabular}

ATCC, Anatomical Therapeutic Chemical Classification; Cl, confidence interval; OR, odds ratio. Regression logistic multinomial. As reference was used the patients who did not present any changes in the Geriatric Depression Scale abbreviate (GDS-15) and Vellore instruments. The $p$-values were adjusted by the variables of smoker, self-perceived health, and number of drugs. ${ }^{*} p<0,05 ;{ }^{\dagger} p<0,01,{ }^{\ddagger} p<0,001$.

\section{DISCUSSION}

Our study revealed a PIM very high frequency rate in community-dwelling middle-age and elderly people, and the rate rose with increasing age. The overall frequency of inappropriate prescription in elderly people showed wide variations: from $2.9 \%$ to $38.5 \%$ [20]. In national studies, the frequency ranged from $20.6 \%$ to
48.0\% [21, 22]. Few studies have been conducted with middle-aged individuals to assess the PIM frequency. Using the PROMPT criteria, developed specifically for this population, the frequency of PIM use was 42.9\% in the Republic of Ireland and $21.1 \%$ in Northern Ireland [23]. Several factors may contribute to this variation. Different countries use different sets of medications due to registration 
issues. There is, hence, no universal list of medications and criteria for assessing the overall medication use by patients.

If the higher frequency of PIM observed is related to SED, this relationship could be driven by a number of factors. Lower socioeconomic status and health literacy can have an adverse effect on the quality of patient-doctor communication and the degree of patient involvement in shared decision making. These circumstances, in turn, may potentially impact on the quality of care and the risk of PIM [24, 25]. Poorer health has been reported in SED areas [26], especially in patients with multimorbidity [11, 27] and exposed to polypharmacy [28], with an increased frequency of long-term conditions including depression, anxiety, pain and coronary heart disease [29]. However, most of these studies were carried out in high-income countries and deserve some careful examination since comparative groups' levels of health literacy and income are very different from those in low- and middle-income countries.

Associated factors for PIM use that remained in the multivariate analysis are, in part, similar to those regularly found in the literature [23, 30]. In some studies, regular self-reported health and being an ex-smoker or current smoker were correlated with use of an increasing number of drugs taken [31, 32], and showed the direct relationship of these variables with the increased frequency of PIM use. The most important predicting factor the probability of PIM use was the polypharmacy; this strong association has also been evident among the middleaged and older populations [23. 33]. The most likely hypothesis is that each drug used had a certain probability of being inappropriate, thus proportionally increasing a subject's likelihood of undergoing an inappropriate therapy with each additional medication. Similarities in PIM use between middle-aged and older people may suggest that interventions aimed at improving inappropriate prescribing could include both age groups. Thus far, studies aimed at improving appropriate polypharmacy have been performed mostly in older patients and have shown some evidence of a reduction in PIM [34, 35].

Cognitive impairment alone, or in conjunction with symptoms of depression, was an associated factor for a PIM prescription. Older people with dementia and/or depression symptoms are particularly vulnerable to use of a large number of drugs, their effects and adverse reactions [14, 36]. Prior research in dementia patients has described that PIM may exacerbate cognitive impairment [37, 38], or relied on prescription medication data to calculate PIM rates in dementia patients [39] or sought to demonstrate that PIM use increases the risk of developing dementia [40]. Perhaps there is a bidirectional relationship between PIM and the risk for dementia. It is therefore important to identify and pay attention to PIM use, put the drug use into perspective and carry out a careful risk-benefit evaluation when considering prescribing to members of this group.

The five most common drugs of PIM used by patients in our sample were omeprazole, glibenclamide, amitriptyline, ibuprofen and diazepam. A recent systematic review and metaanalysis of published studies demonstrated an increased risk of dementia among users of proton pump inhibitors (e.g., omeprazole) and described the possible molecular basis of this association [41]. There is some biological plausibility to the hypothesis that proton pump inhibitors can cross the blood-brain barrier [42]. They may increase both production [43] and degradation [44] of amyloid, at least in animal models, and bind to tau [42]. There is also evidence of reduced levels of B12 and other nutrients among proton pump inhibitors users that could possibly relate to an increased risk of dementia [45]. Prescriptions of high-risk medications expose patients to frequent and severe adverse drug events. Alternative low-risk medications should be prescribed when available. There is, therefore, a need to move towards interventions that can improve the quality of medication prescriptions in all age groups [20].

The patterns of inappropriate prescriptions vary considerably within therapeutic classes. The most frequently reported PIM classes are psychotropic or cardiovascular drugs, since most PIM has been identified in these groups of drugs 
[20,46]. Individuals with cognitive impairment and depression symptoms were at increased use of antiarrhythmics. Amiodarone was the most widely used medication of this class and is associated with multiple toxicities such as thyroid disorders, QT prolongation and pulmonary disorders [16]. In the management of arrhythmias in the elderly, it is important to evaluate the risk and benefit of amiodarone and, when indicated, it is essential to monitor the process of its use to enable the prevention or early identification of adverse events.

There are previous evidence suggesting that patients with cognitive impairment and dementia make greater use of antidepressants with anticholinergic properties (e.g., amitriptyline) and anxiolytics (e.g., benzodiazepines) [47, 48]. Amitriptyline, the third most frequent active agent in our analysis, is often used to treat neuropathic pain. However, it is common to use this medication for psychiatric symptoms, such as a depressive mood or insomnia. The use of antidepressants may cause clinically relevant adverse effects due to their anticholinergic activity, and their ability to induce sedation and orthostatic hypotension, and to stimulate the central nervous system [6]. They should be used with caution, due to the damage they can cause in the psychomotor function, increasing the risk of falls and fractures [49]. Benzodiazepines also were often used in older adults for the treatment of insomnia, depression, or anxiety. But in older adults, they may increase sensitivity to benzodiazepines and decrease metabolism of long-acting agents; in general, all benzodiazepines increase risk of cognitive impairment, delirium, falls, fractures, and motor vehicle crashes in older adults [6]. In addition, they are used often to treat behavioral symptoms of dementia, despite the lack of evidence for their effectiveness [50].

Individuals with only depressive symptoms or with associated cognitive impairment have a greater chance of using medications classified as antihistamines. This finding is particularly worrisome because antihistamines present strong anticholinergic properties and are known to increase the risk of cognitive impairment and falls in older adults [16]. Furthermore, the risk of antihistamine use as a sleep aid may be particularly high in this population given the high prevalence of sleep disturbance in persons with dementia and depression [51]. Unfortunately, despite these risks, the use of non-prescription PIMs is indiscriminate and may go undetected.

We acknowledge that our study has limitations. Our results apply to the population belonging to FHS, that is, focused on those in primary health care, and thus may not be representative of the entire Brazilian population. The PIM pattern in our study is completely influenced by the medications available in the Brazilian Unified Health System. This is due to the striking characteristic of the studied population being individuals with SED conditions. The Brazilian Unified Health System list of available drugs is designed for the general population and the specifics of the elderly have not been considered. In order to assess health conditions, we used as a surrogate the data we thought to be the most reliable: the number of medications used, number of chronic diseases, and self-perceived health status. The lack of data on dosage (acetylsalicylic acid) and the form of release (insulin) could underestimate the consumption of PIM, since these were excluded from the analysis. Thus, for evaluation of the PIM only the active principles of the drugs were taken into account, dose information, renal alterations and drug interactions were not evaluated. The limitations of a cross-sectional and descriptive study should be considered, such as the lack of quality control of the information provided and the lack of crosschecks between variables, and the impossibility of establishing the temporality of the associated factors. Adjustments concerning the lifestyle and health data factors within the multinomial logistic regression models lessened these differences.

This study has shown that PIM is frequent in middle-aged people, a population previously under-researched, and elderly people. By targeting the aging population, the middle-aged individuals will be the focus for health provision in the future. The knowledge of the pharmacoepidemiology of PIM is important information for the promotion of the rational use of drugs in primary health care. 
Cognitive impairment alone, or together with depressive symptoms, was an associated factor for a PIM prescription. Antiarrhythmics (classes I and III), centrally acting antiadrenergics, antihistamines, anxiolytics and antidepressants were the most commonly PIM class used. The prevention and recognition of PIM represents an area of concern in the delivery of healthcare. Conducting medication reviews is a method often recommended to identify and solve PIM, to optimize drug treatment and to improve patient health outcomes. These results could help health professionals and panel experts to plan future Brazilian criteria.

\section{Notes}

This study is part of the result of a doctoral thesis in the Graduate Program in Biomedical Gerontology of the Pontifical Catholic University of Rio Grande do Sul, by one of the authors (VS), entitled "Medicines used by people aged 55 or over in the strategy family health and its association with signs and symptoms of depression and cognitive impairment: a population study".

\section{Funding}

This study was financed in part by the Coordenação de Aperfeiçoamento de Pessoal de NivelSuperior - Brasil (CAPES) - Finance Code 001.

\section{Conflicts of interest disclosure}

The authors declare no competing interests relevant to the content of this study.

\section{Authors' contributions.}

All the authors declare to have made substantial contributions to the conception, or design, or acquisition, or analysis, or interpretation of data; and drafting the work or revising it critically for important intellectual content; and to approve the version to be published.

\section{Availability of data and responsibility for the results}

All the authors declare to have had full access to the available data and they assume full responsibility for the integrity of these results.

\section{REFERENCES}

1. World Health Organization (WHO). Ageing and health [Internet]. Fact sheet N404. Geneva: WHO; 2015 [cited 2018 Oct 6]. Available from: http://www.who. int/mediacentre/factsheets/fs404/en/

2. Cooper JA, Ryan C, Smith SM, Wallace E, Bennett K, Cahir C, Williams D, Teeling M, Fahey T, Hughes CM, (The PROMPT Steering Group). The development of the PROMPT (PRescribing Optimally in Middle-aged People's Treatments) criteria. BMC Health Serv Res. 2014:14:484. https://doi.org/10.1186/s12913-014-0484-6.

3. Cojutti P, Arnoldo L, Cattani G, Brusaferro S, Pea F. Polytherapy and the risk of potentially inappropriate prescriptions (PIPs) among elderly and very elderly patients in three different settings (hospital, community, long-term care facilities) of the Friuli Venezia Giulia region, Italy: are the very elderly at higher risk of PIPs? Pharmacoepidemiol Drug Saf. 2016;25(9):1070-8. https://doi.org/10.1002/pds.4026.

4. Guaraldo L, Cano FG, Damasceno GS, Rozenfeld S. Inappropriate medication use among the elderly: a systematic review of administrative databases. BMC Geriatr. 2011;11:79. https://doi.org/10.1186/1471-2318-11-79.

5. Lucchetti G, Lucchetti AL. Inappropriate prescribing in older persons: A systematic review of medications available in different criteria. Arch Gerontol Geriatr. 2017:68:55-61. https://doi.org/10.1016/j. archger.2016.09.003.

6. American Geriatrics Society 2019 Beers Criteria Update Expert Panel. American Geriatrics Society 2019 Updated AGS Beers Criteria for Potentially Inappropriate Medication Use in Older Adults. J Am Geriatr Soc. 2019;67:674-94. https://doi.org/10.1111/jgs.15767.

7. Holt S, Schmiedl S, Thürmann PA. Potentially inappropriate medications in the elderly: the PRISCUS list. Dtsch Arztebl Int. 2010;107(31-32):543-51. https://doi.org/10.3238/arztebl.2010.0543.

8. Kuhn-Thiel AM, Weiß C, Wehling M, FORTA authors/expert panel members. Consensus validation of the FORTA (Fit fOR The Aged) List: a clinical tool for increasing the appropriateness of pharmacotherapy in the elderly. Drugs Aging. 2014:31(2):131-40. https://doi.org/10.1007/s40266-013-0146-0.

9. Renom-Guiteras A, Meyer G, Thürmann PA. The EU(7)-PIM list: a list of potentially inappropriate medications for older people consented by experts from seven European countries. Eur J Clin Pharmacol. 2015:71(7):861-75. https://doi.org/10.1007/ s00228-015-1860-9.

10. O'Mahony D, O'Sullivan D, Byrne S, O'Connor MN, Ryan C, Gallagher P. STOPP/START criteria for potentially inappropriate prescribing in older people: version 2. Age Ageing. 2015:44(2):213-8. https://doi. org/10.1093/ageing/afu145. 
11. Barnett K, Mercer SW, Norbury M, Watt G, Wyke S, Guthrie B. Epidemiology of multimorbidity and implications for health care, research, and medical education: a cross-sectional study. Lancet. 2012;380:3743. https://doi.org/10.1016/S0140-6736(12)60240-2.

12. Gutzmann H, Qazi A. Depression associated with dementia. Z Gerontol Geriatr. 2015:48(4):305-11. https://doi.org/10.1007/s00391-015-0898-8.

13. Alic A, Pranjic N, Ramic E. Polypharmacy and decreased cognitive abilities in elderly patients. Med Arh. 2011;65(2):102-5.

14. Lee D, Martini N, Moyes S, Hayman K, Zolezzi $\mathrm{M}$, Kerse N. Potentially inappropriate medication use: the Beers' Criteria used among older adults with depressive symptoms. J Prim Health Care. 2013:5(3):182-90. https://doi.org/10.1071/HC13182.

15. Disalvo D, Luckett T, Agar M, Bennett A, Davidson PM. Systems to identify potentially inappropriate prescribing in people with advanced dementia: a systematic review. BMC Geriatr. 2016;16:114. https:// doi.org/10.1186/s12877-016-0289-Z.

16. American Geriatrics Society 2015 Beers Criteria Update Expert Panel. American geriatrics society 2015 updated beers criteria for potentially inappropriate medication use in older adults. J Am Geriatr Soc. 2015:63(11):2227-46. https://doi.org/10.1111/jgs.13702.

17. World Health Organization (WHO). WHO Collaborating Centre for Drug Statistics Methodology [Internet]. Guidelines for ATC classification and DDD assignment 2017. Geneva: WHO; 2017 lcited 2018 Oct 10]. Available from: https://www.whocc.no/filearchive/publications/2017_guidelines_web.pdf

18. Lesher EL, Berryhill JS. Validation of the Geriatric Depression Scale-Short Form among inpatients. J Clin Psychol. 1994:50:256-60.

19. Stanley R, Kuruvilla A, Kumar S, Gayathri K, Mathews P, Abraham V, Rajkumar A, Jacob KS. The Vellore screening instruments and strategies for the diagnosis of dementia in the community. Int Psychogeriatr. 2009;21(3):539-47. https://doi.org/10.1017/ S104161020900903X.

20. Opondo D, Eslami S, Visscher S, de Rooij SE, Verheij R, Korevaar JC, Abu-Hanna A. Inappropriateness of medication prescriptions to elderly patients in the primary care setting: a systematic review. PLoS One. 2012;7(8):e43617. https://doi.org/10.1371/journal.pone.0043617.

21. Cassoni TCJ, Corona LP, Romano-Lieber NS, Secoli SR, Duarte YAO, Lebrao ML. Uso de medicamentos potencialmente inapropriados por idosos do Municipio de São Paulo, Brasil: Estudo SABE. Cad Saude Publica. 2014:30(8):1708-20. https://doi. org/10.1371/journal.pone.0043617.

22. Lopes LM, Figueiredo TP, Costa SC, Reis AM. Use of potentially inappropriate medications by the elderly at home. Cien Saude Colet. 2016;21(11):3429-38 https://doi.org/10.1590/1413-812320152111.14302015.
23. Cooper JA, Moriarty F, Ryan C, Smith SM, Bennett K, Fahey T, Wallace E, Cahir C, Williams D, Teeling $M$, Hughes CM. Potentially inappropriate prescribing in two populations with differing socio-economic profiles: a cross-sectional database study using the PROMPT criteria. Eur J Clin Pharmacol. 2016;72(5):58391. https://doi.org/10.1007/s00228-015-2003-z.

24. Willems S, De Maesschalck S, Deveugele M, Derese A, De Maeseneer J. Socio-economic status of the patient and doctor-patient communication: does it make a difference? Patient Educ Couns. 2005:56(2):13946. https://doi.org/10.1016/j.pec.2004.02.011.

25. Smith SK, Dixon A, Trevena L, Nutbeam D, McCaffery KJ. Exploring patient involvement in healthcare decision making across different education and functional health literacy groups. Soc Sci Med. 2009;69(12):180512. https://doi.org/10.1016/j.socscimed.2009.09.056.

26. Mercer SW, Watt GC. The inverse care law: clinical primary care encounters in deprived and affluent areas of Scotland. Ann Fam Med. 2007:5:503-10. https://doi.org/10.1370/afm.778.

27. Charlton J, Rudisill C, Bhattarai N, Gulliford M. Impact of deprivation on occurrence, outcomes and health care costs of people with multiple morbidity. J Health Serv Res Policy. 2013;18:215-23. https://doi. org/10.1177/1355819613493772.

28. Payne RA, Avery AJ, Duerden M, Saunders CL, Simpson CR, Abel GA. Prevalence of polypharmacy in a Scottish primary care population. Eur J Clin Pharmacol. 2014;70(5):575-81. https://doi.org/10.1007/ s00228-013-1639-9.

29. McLean G, Gunn J, Wyke S, Guthrie B, Watt GC, Blane DN, Mercer SW. The influence of socioeconomic deprivation on multimorbidity at different ages: a cross-sectional study. Br J Gen Pract. 2014;64(624):e440-7. https://doi.org/10.3399/bjgp14X680545.

30. Bongue B, Naudin F, Laroche ML, Galteau MM, Guy C, Guéguen R, Convers JP, Colvez A, Maarouf $\mathrm{N}$. Trends of the potentially inappropriate medication consumption over 10 years in older adults in the East of France. Pharmacoepidemiol Drug Saf. 2009:18(12):1125-33. https://doi.org/10.1002/pds.1762.

31. Brekke M, Hunskaar S, Straand J. Self-reported drug utilization, health, and lifestyle factors among 70-74 year old community dwelling individuals in Western Norway. The Hordaland Health Study (HUSK). BMC Public Health. 2006;6:121. https://doi. org/10.1186/1471-2458-6-121.

32. Richardson K, Kenny RA, Bennett K. The effect of free health care on polypharmacy: a comparison of propensity score methods and multivariable regression to account for confounding. Pharmacoepidemiol Drug Saf. 2014:23(6):656-65. https://doi.org/10.1002/pds.35.90.

33. Bradley MC, Fahey T, Cahir C, Bennett K, O'Reilly D, Parsons C, Hughes CM. Potentially inappropriate prescribing and cost outcomes for older people: a cross-sectional study using the Northern Ireland Enhanced Prescribing Database. Eur J Clin Pharmacol. 2012;68(10):1425-33. https://doi.org/10.1007/s00228-012-1249-y. 
34. Patterson SM, Hughes C, Kerse N, Cardwell CR, Bradley MC, Ryan C, Hughes C. Interventions to improve the appropriate use of polypharmacy for older people. Cochrane Database Syst Rev. 2014:(10):CDo08165. https://doi. org/10.1002/14651858.CD008165.pub3.

35. Cadogan CA, Ryan C, Hughes CM. Appropriate Polypharmacy and Medicine Safety: When Many is not Too Many. Drug Saf. 2016;39(2):109-16. https:// doi.org/10.1007/s40264-015-0378-5.

36. Koyama A, Steinman M, Ensrud K, Hillier TA, Yaffe $\mathrm{K}$. Ten-year trajectory of potentially inappropriate medications in very old women: importance of cognitive status. J Am Geriatr Soc. 2013;61(2):258-63. https://doi.org/10.1111/jgs.12093.

37. Weston AL, Weinstein AM, Barton C, Yaffe K. Potentially inappropriate medication use in older adults with mild cognitive impairment. J Gerontol A Biol Sci Med Sci. 2010; 65:318-21. https://doi.org/10.1093/gerona/glp158.

38. Toscani F, Di Giulio P, Villani D, Giunco F, Brunelli C, Gentile S, Finetti S, Charrier L, Monti M, van der Steen JT, End of Life Observatory-Prospective Study on Dementia Patients Care Research Group. Treatments and prescriptions in advanced dementia patients residing in long-term care institutions and at home. J Palliat Med. 2013;16(1):31-7. https://doi. org/10.1089/jpm.2012.0165.

39. Sönnerstam E, Sjölander M, Gustafsson M. An evaluation of the prevalence of potentially inappropriate medications in older people with cognitive impairment living in Northern Sweden using the EU(7)-PIM list. Eur J Clin Pharmacol. 2017:73(6):73542. https://doi.org/10.1007/s00228-017-2218-2.

40. Zhong G, Wang Y, Zhang Y, Zhao Y2. Association between benzodiazepine use and dementia: a meta-analysis. PLoS One. 2014;10(5):e0127836. https://doi. org/10.1371/journal.pone.0127836.

41. Wijarnpreecha K, Thongprayoon C, Panjawatanan $\mathrm{P}$, Ungprasert P. Proton pump inhibitors and risk of dementia. Ann Transl Med. 2016;4(12):240. https://doi. org/10.21037/atm.2016.06.14

42. Rojo LE, Alzate-Morales J, Saavedra IN, Davies P. Maccioni RB. Selective interaction of lansoprazole and astemizole with tau polymers: potential new clinical use in diagnosis of Alzheimer's disease. J Alzheimers Dis. 2010;19(2):573-89. https://doi. org/10.3233/JAD-2010-1262.

43. Badiola N, Alcalde V, Pujol A, Münter LM, Multhaup G, Lleó A, Coma M, Soler-López M, Aloy P. The proton-pump inhibitor lansoprazole enhances amyloid beta production. PLoS One. 2013;8(3):e58837. https://doi.org/10.1371/journal.pone.0058837.

44. Fallahzadeh MK, Borhani Haghighi A, Namazi MR Proton pump inhibitors: predisposers to Alzheimer disease? J Clin Pharm Ther. 2010;35(2):125-6. https:// doi.org/10.1111/j.1365-2710.2009.01100.x.
45. Lam JR, Schneider JL, Zhao W, Corley DA. Proton pump inhibitor and histamine 2 receptor antagonist use and vitamin B12 deficiency. JAMA. 2013:310(22):2435-42. https://doi.org/10.1001/jama.2013.280490.

46. Schubert I, Küpper-Nybelen J, Ihle P, Thürmann P. Prescribing potentially inappropriate medication (PIM) in Germany's elderly as indicated by the PRISCUS list. An analysis based on regional claims data. Pharmacoepidemiol Drug Saf. 2013:22(7):719-27. https://doi.org/10.1002/pds.3429.

47. Johnell K. Inappropriate drug use in people with cognitive impairment and dementia: A systematic review. Curr Clin Pharmacol. 2015;10:178-84. https:// doi.org/10.2174/1574884710666150609154741.

48. Cross AJ, George J, Woodward MC, Ames D, Brodaty H, Ilomäki J, Elliott RA. Potentially inappropriate medications and anticholinergic burden in older people attending memory clinics in Australia. Drugs Aging. 2016;33:37-44. https://doi.org/10.1007/ s40266-015-0332-3.

49. Vitry Al, Hoile AP, Gilbert AL, Esterman A, Luszcz $M A$. The risk of falls and fractures associated with persistent use of psychotropic medications in elderly people. Arch Gerontol Geriatr. 2010;50(3):e1-e4. https://doi.org/10.1016/j.archger.2009.04.004.

50. Tampi RR, Tampi DJ. Efficacy and tolerability of benzodiazepines for the treatment of behavioral and psychological symptoms of dementia: A systematic review of randomized controlled trials. Am J Alzheimers Dis Other Demen. 2014;29:565-74. https://doi. org/10.1177/15333317514524813.

51. Thorpe JM, Thorpe CT, Kennelty KA, Gellad WF, Schulz R. The impact of family caregivers on potentially inappropriate medication use in noninstitutionalized older adults with dementia. Am J Geriatr Pharmacother. 2012;10(4):230-41. https://doi. org/10.1016/j.amjopharm.2012.05.001.

\section{Vanessa Sgnaolin:}

Pharmacist, Specialist in Health with emphasis on Clinical and Toxicological Analysis, MD in Health Sciences and PhD in Biomedical Gerontology. Postdoctoral student of the Graduate Program in Biomedical Gerontology at Pontifical Catholic University of Rio Grande do Sul (PUCRS).

\section{Paula Engroff:}

Pharmacist, Specialist in Teaching in Higher Education and PhD in Biomedical Gerontology. Pharmacist at the Biochemistry and Molecular Genetics Laboratory of the Institute of Geriatrics and Gerontology at Pontifical Catholic University of Rio Grande do Sul (PUCRS). 


\section{Natascha Melo Linkievicz:}

Pharmacy Student at Pontifical Catholic University of Rio Grande do Sul (PUCRS). Scientific Initiation Scholarship at the Biochemistry and Molecular Genetics Laboratory of the Graduate Program in Biomedical Gerontology at PUCRS

\section{Irenio Gomes:}

Physician, MD in Cellular and Molecular Biology, PhD in Medicine and Postdoctoral at Hôpital de Bicêtre in Paris.

\section{Alfredo Cataldo Neto:}

Physician, Specialist in Psychiatry, Psychoanalyst and PhD in Clinical Medicine. Professor of School of Medicine at Pontifical Catholic University of Rio Grande do Sul (PUCRS) and researcher at the PUCRS Institute of Geriatrics and Gerontology.

\section{Mailing address}

\section{Vanessa Sgnaolin}

Pontifícia Universidade Católica do Rio Grande do Sul Ipiranga 6681, Prédio 40, $8^{\circ}$ andar

Partenon 90619-900

Porto Alegre, RS, Brasil. 